\title{
Recurrent Hemophagocytic Lymphohistiocytosis
}

National Cancer Institute

\section{Source}

National Cancer Institute. Recurrent Hemophagocytic Lymphohistiocytosis. NCI

Thesaurus. Code C153296.

The reemergence of hemophagocytic lymphohistiocytosis after a period of remission. 